\title{
UCRL-TR-208891
}

LAW RENCE LIVERMORE N A T IO N A L LABORATORY
Designer Nanocellular Materials for Laser Targets and Other DNT Applications

J. H. Satcher, Jr, L. M. Hsiung, T. F. Baumann, R. S. Maxwell, S. C. Chinn, A. M. Hodge, J. Biener, R. L. Landingham

January 7, 2005 
This document was prepared as an account of work sponsored by an agency of the United States Government. Neither the United States Government nor the University of California nor any of their employees, makes any warranty, express or implied, or assumes any legal liability or responsibility for the accuracy, completeness, or usefulness of any information, apparatus, product, or process disclosed, or represents that its use would not infringe privately owned rights. Reference herein to any specific commercial product, process, or service by trade name, trademark, manufacturer, or otherwise, does not necessarily constitute or imply its endorsement, recommendation, or favoring by the United States Government or the University of California. The views and opinions of authors expressed herein do not necessarily state or reflect those of the United States Government or the University of California, and shall not be used for advertising or product endorsement purposes.

This work was performed under the auspices of the U.S. Department of Energy by University of California, Lawrence Livermore National Laboratory under Contract W-7405-Eng-48. 


\section{Designer Nanocellular Materials for Laser Targets and Other DNT Applications}

Tracking Number: 04-ERD-022

Principal Investigator: Joe H. Satcher, Jr.

Co-investigators: Luke M. Hsiung, Theodore F. Baumann, Robert S. Maxwell, Sarah C. Chinn, Andrea M. Hodge, Juergen Biener, Richard L. Landingham

Overview. This document and the accompanying manuscripts summarize the technical accomplishments of our one-year LDRD-ER effort, a project that has since been incorporated into a larger LDRD-SI for FY05. The objective of this effort was to develop a predictive synthetic capability for the preparation of materials with cellular architectures (sub-micron pore or cell sizes and relative densities less than $10 \%$ of full density) not attainable by conventional methods. The ability to reliably prepare these nanocellular materials and control their bulk physical properties (e.g. mechanical strength) would be a considerable advance in the areas of porous materials and its impact would cut across many existing LLNL investments. One significant area related to the Laboratory mission that would benefit is the design of new materials for high energy density physics (HEDP) targets. Current synthetic techniques do not allow for the preparation of foams that meet all of the current and projected compositional and mechanical requirements of these experiments. This project focused on two main types of materials: inorganic sol-gel materials and nanocellular metal foams. The following sections describe the project goals for these two types of materials as well as the progress made towards these goals in FY04. These sections also provide context for the three publications that have been included in this final report.

Structure Control in Sol-Gel Materials. The sol-gel process involves the transformation of reactive monomers into nanometer-sized clusters that crosslink to form a three-dimensional gel network. Due to the colloidal nature of the process, sol-gel materials typically possess submicron architectures that are defined by randomly interconnected particles with diameters in the 1-100 $\mathrm{nm}$ range. Due to their unique microstructure, materials prepared by the sol-gel process are being investigated for a wide range of applications including catalysis, separation technology, ceramics, sensors/detectors and nano-electronics. One of the shortcomings of current sol-gel chemistry, however, is the inability to reliably control and predict the bulk physical properties of these materials. The final properties of the sol-gel material are closely associated with several factors, such as precursors, catalyst and reaction conditions. These synthetic variables can affect the kinetics of nucleation, particle growth and the organization of the gel network. These parameters, in turn, have a pronounced influence on the macroscopic properties (e.g. mechanical strength, surface area, porosity) of the sol-gel products. Control over bulk physical properties, therefore, requires a fundamental understanding of the mechanisms by which solution species form, aggregate, and assemble into the gel network, and how these processes influence the physical properties of the sol-gel materials. The development of such relationships has not yet been fully realized for these materials.

In order to obtain this detailed insight, an in-process characterization technique is required that can probe the structure and composition of the solution species as well as monitor their organization into the final gel microstructure. Nuclear magnetic resonance spectroscopy (NMR) is ideally suited for this level of characterization since the technique provides characteristic signatures that can track changes in both solid and solution phases in an elementally selective and non-destructive manner. Our goal in this effort is to establish a correlation between 
synthetic variables and material properties analogous to those used to develop structure-property relationships in organic polymer systems. We are using solution, gel and solid-state NMR techniques to follow the transformations associated with the sol-gel process and the information derived from these experiments should provide detailed insight into the relationship between synthesis and the macroscopic properties in inorganic sol-gel materials. Such an advance would fundamentally change the way these materials are prepared and, as a result, expand the technological potential of sol-gel science. As a first step in this effort, we are applying these NMR techniques to monitor structure formation in aluminum oxide $\left(\mathrm{Al}_{2} \mathrm{O}_{3}\right)$ aerogels. For FY04, our goals were to: (1) prepare $\mathrm{Al}_{2} \mathrm{O}_{3}$ aerogels from formulations that produce at least two distinct structural morphologies, (2) use solution NMR techniques to follow reactions that occur during sol formation and (3) use solid-state NMR techniques to characterize the microstructure of the final sol-gel material. Since the start of this effort, we have developed an $\mathrm{Al}_{2} \mathrm{O}_{3}$ aerogel system that, by changing a single synthetic variable, generates a set of materials whose morphology and mechanical properties are dramatically different. We have also characterized these $\mathrm{Al}_{2} \mathrm{O}_{3}$ systems using both solution and solid-state NMR techniques. The bulk of this work is described in the attached manuscript entitled "Synthesis of High Surface Area Alumina Aerogels without the Use of Alkoxide Precursors".

Nanocellular Metal Foams. Commercial metal foams are synthesized by a wide variety of methods and typically have relative density in the range of 0.03 to 0.3 , and cell sizes in the range of 2 to $10 \mathrm{~mm}$. Current foaming techniques, however, are inadequate for synthesizing metal foams with nanocellular architecture. The goal of this project is to establish a new foaming technology for synthesizing novel micro- or nanocellular metal and composite foams. We are utilizing a method known as dealloying to control the cell sizes in porous metals. This approach has been used to synthesize novel foams from high $\mathrm{Z}$ metals such as Au and Pt. The dealloying method involves a phase separation process (spinodal decomposition) within bulk $\mathrm{Au}-\mathrm{Ag}, \mathrm{Au}-$ $\mathrm{Cu}$, and $\mathrm{Pt}-\mathrm{Cu}$ alloys through heat treatment at elevated temperatures. Nanoporous $\mathrm{Au}$ or $\mathrm{Pt}$ sponges (open-cell foam) can then be produced by selectively leaching out the less noble component of the alloy, i.e. $\mathrm{Ag}$ from $\mathrm{Au}-\mathrm{Ag}$ alloy or $\mathrm{Cu}$ from $\mathrm{Pt}-\mathrm{Cu}$ alloy, using an electrochemical process. An additional goal of this effort is to advance knowledge of materials science as a result of the investigation of surface-controlled foaming mechanisms and surfacecontrolled deformation mechanisms and kinetics within the novel foams under quasi-static and dynamic pressure conditions. The grain structure, cellular architecture and mechanical properties (modulus, strength, creep strength, strain-rate sensitivity and dynamic behavior) of these nanocellular metal foams will be characterized by a variety of techniques. Emphasis is being placed on correlating measured properties with structural parameters and mechanical properties of the foams. For FY04, we proposed to initiate de-alloying efforts to: (1) reproduce nanocellular $\mathrm{Au}$ foam work (relative density $>20 \%$ ), (2) characterize architecture, microstructure, and mechanical properties of nanocellular Au. Since the start of this effort, we have prepared dealloyed Au foams at $40 \%$ and $30 \%$ relative density and characterized the structural and mechanical properties of these materials. These efforts are described in the attached manuscripts entitled "Nanoporous Au: A high yield strength material" and "Monolithic Nanocrystalline Au Fabricated by the Compaction of Nanoscale Foam".

Work was performed under the auspices of the U.S. Department of Energy by Lawrence Livermore National Laboratory under contract number W-7405-ENG-48. The project (04-ERD022) was funded by the Laboratory Directed Research and Development Program at LLNL. 